\title{
Sperm Cryopreservation in Brown Bear (Ursus arctos): Preliminary Aspects
}

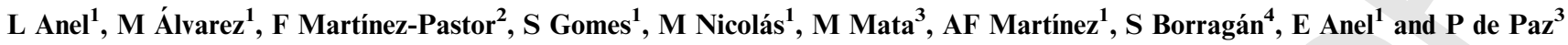 \\ ${ }^{1}$ ITRA-ULE, Animal Reproduction and Obstetrics, University of León, León; ${ }^{2}$ Biology of Reproduction Group, National Wildlife Research Institute \\ (IREC) (UCLM-CSIC-JCCM), Albacete; ${ }^{3}$ ITRA-ULE, Molecular Biology, University of León, León; ${ }^{4}$ Cabárceno Nature Park (Cantur SA), \\ 1 Cantabria, Spain
}

\begin{abstract}
Contents
The development of sperm cryopreservation procedures in brown bear is the basis for establishing a specific genetic resource bank aimed at the preservation of a Cantabric brown bear population, which is seriously threatened. Several issues complicate the development of these cryopreservation procedures: lack of previous specific studies, a high incidence of urospermia and spermagglutination observed in bear ejaculates. Moreover, the availability of individuals for research from these threatened populations is problematic. In the case of the Cantabric brown bear, we have used males from other populations, but of the same species, as surrogates, to carry out a direct extrapolation of the results. Urospermia Moreover, $70 \%$ of the ejaculates are urine contaminated and spermagglutination have a detrimental effect on post-thawing cell quality recovery in this species. Considering the high value of these samples (autochthonous population with few individuals), a pre-selection of the ejaculates is not a viable alternative. Preventive methods reducing the mentioned detrimental effects need to be developed. On the basis of previous data, we can suppose that bear spermatozoa resist freezing injuries well. Nevertheless, because of the scarcity of this information, it is necessary to conduct further research on bear semen freezing under field conditions. Epidydimal spermatozoa can be important for genetic resource banking of threatened populations and thus specific cryobiological protocols need to be assayed. To date, 168 brown bear ejaculates have been frozen by the ITRA-ULE group at the University of León (Spain) in the development of methodologies for the preservation of brown bear sperm.
\end{abstract}

\section{Introduction}

Assisted reproduction is currently one of the most reliable options for ex situ reproduction programs for threatened species and breeds. We have developed a series of strategies to establish a germplasm bank for the Cantabric population of brown bear (Ursus arctos). Our general objective is to develop specific methodologies for the use of artificial insemination in brown bear, considering sperm cryopreservation as our first goal towards creating a genetic reserve for the species (Anel et al. 2005).

Cantabric brown bear is the objective of our project for two reasons: (i) the geographical proximity of the Cantabric brown bear population to the University of León; and (ii) this bear population constitutes a threatened nucleus.

At present, six of the eight bear species are at risk of disappearing. Only North American black bear (Ursus americanus), with a population of 900000 individuals, is safe in its geographical area (Canada, United States and Mexico). In fact, they are legally hunted in most of their territories. According to a recent evaluation of the
Specialists Groups of Bears and Polar Bears, Asia and South America are the areas that need urgent conservation measures (IUCN Red List of Threatened Species, IUCN 2007).

Brown bears are not catalogued as threatened worldwide because large populations exist in Russia, Canada, Alaska and some regions of Europe (IUCN 2007). However, in regions of Southern Europe and Central and Southern Asia, there are only very small populations, which are isolated and highly vulnerable. Therefore, most brown bear populations are being protected by law. For instance, the Threatened Species Conservation Act of the USA considers grizzly bears (Ursus arctos horribilis) threatened outside Alaska.

\section{Why brown bear?}

The brown bear is an endangered species in Spain and the last individuals [around 130 animals according to the Fundacion Oso de Asturias (personal communication)] survive in two separate subpopulations in the Cantabric Mountains (Northern Spain). The brown bear is considered at risk of extinction by Spanish law (Real Decreto 439/1990, regulation of the National Catalogue of Endangered Species) and the European Union has classified it as endangered and among the priority species (Council Directive 92/43/EEC, annexes II and IV). These bears are unique, as they represent a very pure lineage, closely related to the Scandinavian subpopulations and the 'Western branch' of the phylogenetic tree of European brown bears (Taberlet and Bouvet 1994; Laikre et al. 1996). Their situation is critical because of the small size of the two subpopulations and also because of the high risk of inbreeding (Taberlet and Bouvet 1994). Thanks to conservation measures, an increase in the population has been observed in recent years. However, further initiatives, such as the genetic interchange between the two subpopulations, are needed (Anel et al. 1999; GarciaGaritagoitia et al. 2003). The application of sperm banking would considerably improve the management of the available genetic resources.

\section{Genetic resource banking for the Cantabric brown bear}

Genetic Resource Banks offer benefits to species conservation programmes in terms of maintaining biodiversity and helping the conservation of highly endangered species (Holt et al. 1996; Wildt 1997, 2000; Montgomery 2002). A limitation to developing germplasm banks is the lack of information for accurate

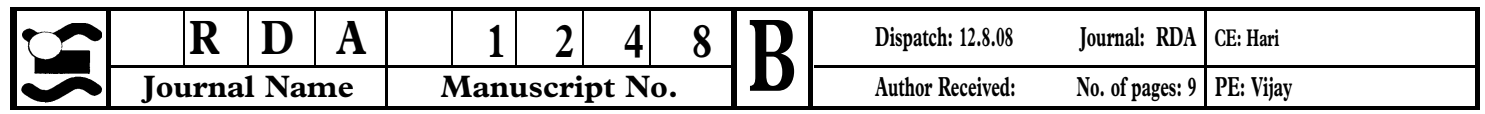


collection, assessment, preservation and application of gametes and embryos. Technological development has usually been carried out on the basis of the previous experience in domestic species. Nevertheless, the great variety of methods and the different results obtained when they are applied to other species lead to the conclusion that it is necessary to develop specific freezing protocols for each group of animals (Fickel 3et al. 2005).

A germplasm bank for the Cantabric brown bear began with a semen freezing programme (Anel et al. 2005), which allowed doses of semen from many individuals to be stored and also artificially inseminated. To do this we need to know about male sexual physiology, spermatozoa quality, sperm preservation methods, female sexual cycle and specific insemination protocols. The acquisition of this knowledge requires a large number of animals and unfortunately, this represents an important handicap when working with threatened species and populations.

The use of animals from classic zoological collections also has its problems, with a limited number of animals and significant differences with field conditions. Furthermore, studies on the sperm characteristics of wild mammals have shown considerable differences between species, even related ones (Leibo and Songsasen 2002). This variability can prevent the establishment of genetic resource banks in many wild species or populations, because of the lack of proper protocols. For example, the American black bear was proposed as a model for the study of embryo transfer (Boone et al. 1999), but discrepancies between the results obtained with the same methodologies in related bear species have been noticed (Dehnhard et al. 2006).

\section{Cabarceno Nature Park: the best place to work}

In the case of Cantabric brown bear, we can work with animals from the same species, extracted from nonthreatened populations, thus facilitating the direct extrapolation of the tested methods. Cabarceno Nature Park meets all the requirements to be a reference as an experimental centre. Briefly, the Cabarceno Nature Park houses brown bears under semi-free ranging conditions (55-60 animals in 36 ha), closely simulating field conditions (allowing to conduct teleanaesthesia and different cryobiological procedures, etc). The high number of available males ( 27 adults) means that a reliable experimental design can be obtained. Up to now, 184 captures have been carried out under diverse anaesthetic protocols, while studying different electroejaculation methods (324 tests) and several alternative protocols for handling and freezing bear sperm (168 ejaculates were frozen).

\section{Challenges in Obtaining and Working with Brown Bear Electroejaculates}

The collection of good quality brown bear ejaculates raises questions because of the scarcity of information on assisted reproduction in this species. It is essential to consider the problems related to capture by teleanaesthesia, the optimum season to collect the ejaculates (seasonality), contamination of the ejaculate with urine (urospermia) and spermagglutination.

\section{Teleanaesthesia}

Adaptation to field conditions is basic for the development of effective anaesthetic procedures. In the capture and immobilization of the animals, the most important factors are safety and effectiveness. In most publications, bears are immobilized under captive conditions. The use of ketamine $(10-15 \mathrm{mg} / \mathrm{kg}$ Chen et al. 2007; $7 \mathrm{mg} / \mathrm{kg}$ Zhang et al. 2005), the combinations tiletamine and zolazepam (7-9 mg/kg Ishikawa et al. 2002; Kojima et al. 2001; Okano et al. 2006), tiletamine and midazolam or ketamine and xylazine $(8-10 \mathrm{mg} / \mathrm{kg}$ and $1.2-1.8 \mathrm{mg} / \mathrm{kg}$ Chen et al. 2007) are good options because short induction times are not needed. Okano et al. (2004), while working with free-ranging trapped Japanese black bear (Ursus thibetanus japonicus), anaesthetized the animals with higher doses than those used in captive animals. Other protocols employed in freeranging bears used ketamine and xylazine [black bear, Addison and Kolenosky 1979; polar bear (Ursus maritimus), Lee et al. 1981; and Hokkaido brown bear (Ursus arctos yesoensis), Tsubota et al. 1991], requiring lengthy anaesthetic induction times (13-47 min) and presenting a high variability. Therefore, the inability to achieve a recurrent anaesthetic protocol and a short induction time would imply a high escape risk when applying on free-ranging Cantabric brown bears. The habitat of these bears has a very rough orography and so it is necessary to design anaesthetic protocols with a very short induction time (2-3 min), to prevent lesions during the initial phases of anaesthesia.

Our teleanaesthesia trials in brown bear using tiletamine-zolazepam $(7 \mathrm{mg} / \mathrm{kg})$ and ketamine $(2 \mathrm{mg} / \mathrm{kg})$ combinations (Garcia-Macias et al. 2006a) showed a considerable reduction in induction times in comparison 4 with published data $(8.1 \pm 4.2 \mathrm{~min}$, unpublished data $)$. Nevertheless, new combinations should be assessed to shorten further the induction time when capturing of wild bears. At present, we are assessing new drug combinations (i.e., medetomidine/Telazol) and agents that accelerate the drug absorption, to reduce the anaesthesia induction times.

\section{Seasonality}

Seasonality affects the quality and quantity of spermatozoa collected (Garcia-Macias et al. 2006a) and so it is an important factor to consider in the collection of sperm samples. Some mammals have a complete reproductive arrest during their annual cycle; males undergo testicular quiescence and suppression of semen production followed by recrudescence and a sexually active period (Suzuki et al. 1992; Blottner et al. 1995; Martinez-Pastor et al. 2005b)

Reproductive seasonality is very evident in bears, with a high degree of variability among different species. Bears in temperate regions have a seasonal reproductive cycle, with a mating season of approximately 23 months (Dehnhard et al. 2006). The reproductive season of the Hokkaido brown bear spans from early 
May to July (Tsubota et al. 1985), while in American black bear it comprises from May to August (Garshelis and Hellgren 1994). Sun bears in Malaysia (Helarctos malayanus) breed seasonally (August and September) in association with the rainy season (Onuma et al. 2002). Seasonal changes are also documented in the giant panda bear (Ailuropoda melanoleuca) (Moore et al. 1984), with a better seminal quality and larger testicle size in spring than in summer, autumn or winter. Testicle size in bears in temperate regions varies seasonally and spermatogenesis and steroidogenesis are maximum before and during the breeding season (MayJuly), as is documented for grizzly bear (Craighead et al.

51969) and black bear (Erickson and Nellor 1964). Howell-Skalla et al. (2002) studied serum concentrations of testosterone, which showed that they are three times greater in April than in May, June and October. Tsutsui et al. (2006) determined that plasma concentrations of testosterone in giant panda bears are markedly lower after the oestrus period in comparison with those observed before and during the oestrus. In the brown bears housed in the Cabárceno Nature Park, we have observed that the testosterone peak occurs in March and that the mating season spans from late April to late June with slight interannual variations.

\section{Urospermia}

Urine contamination of the ejaculates is frequent in some species (horse, Althouse et al. 1989; man, McMahon et al. 2004) and occasional in others. During electroejaculation, urospermia can occur in species where urine contamination does not occur physiologically (ursids: Kojima et al. 2001; Okano et al. 2004; Martinez-Pastor et al. 2003; felines: Pukazhenthi et al. 2000). Urine contamination is very frequent in bear ejaculates obtained by electroejaculation; however, few studies exist about its harmful effects. Urine contamination alters the $\mathrm{pH}$ and osmolarity of the seminal sample and causes a drop in motility, damages the plasmalemma and reduces the fertility of the ejaculate (Makler et al. 1981; Kim and Kim 1998). The degree of damage depends on urine $\mathrm{pH}$ and osmolarity, as well as on the toxic effect of urea and other components (Griggers et al. 2001). In some species, hypoosmotic conditions are more harmful than hyperosmotic ones (Blackshaw and Emmens 1951; Pommer et al. 2002).

Reduction in motility caused by $\mathrm{pH}$ alteration is greater in acidic than in alkaline conditions. However, immobile spermatozoa in low $\mathrm{pH}$ are capable of moving again when the $\mathrm{pH}$ is returned to a physiological level, whereas alkaline $\mathrm{pH}$ effects are irreversible (Makler 6et al. 1981). When the $\mathrm{pH}$ is nearly physiological (neutral or slightly alkaline), the harmful effects of urine are considerably reduced (Wirtu et al. 2008).

In black bear, Kojima et al. (2001) found that only $67 \%$ of the collected ejaculates were contaminated and that contaminated samples had significantly smaller percentages of motility than non-contaminated ones $(13 \%$ vs $73 \%)$. Okano et al. (2004) observed contamination in all the collected black bear ejaculates, although, in many cases, it was very low and sperm viability was not seriously affected. These authors assumed that urine osmolarity was always high and did not observe evidence of damage after centrifugating the semen and returning it to isoosmotic conditions. Other authors found serious damage when reverting hypertonicity in domestic cats (Pukazhenthi et al. 2000). Chen et al. (2007) obtained contaminated semen in 11 of 19 electroejaculated black bears (15 contaminated ejaculates of 23).

Our data (unpublished) in brown bear semen show that the total percentage of contaminated ejaculates was low $(35.5 \%)$, compared to that observed by authors in other bear species. This low contamination is a consequence of the application of different corrective measures (see below), but the first experiences rendered $70 \%$ of contaminated ejaculates.

Semen contaminated with urine has a significantly lower $\mathrm{pH}$ than non-contaminated semen (5.8 vs 7.5 ) (Kojima et al. 2001). Our results showed that the $\mathrm{pH}$ of non-contaminated samples varied between 7.6 and 8 (unpublished data), slightly higher than that observed by Chen et al. (2007) in asiatic black bear (7.1).

\section{Spermagglutination}

Spermatozoa agglutination happens frequently in brown bear ejaculates (Kojima et al. 2001) and interferes with the assessment of sperm quality, makes handling and preservation difficult and probably affects the freezability of the sample, although its effect on fertility is yet to be proven (Bollwein et al. 2004). Spermatozoa can agglutinate among themselves (head-head or head-tail) or to other particles present in the sample. For instance, fimbriated bacteria can cause agglutination in motile spermatozoa, by attaching to the glycoproteins present 7 on their surface (Monga and Robertst 1994). The incidence and intensity of agglutination depend on several factors: individual, season, or ejaculate handling. In brown bears, we have quantified agglutination in $44.6 \%$ of the ejaculates (high level in $16.8 \%$, unpublished data).

\section{Is Pre-Freezing Ejaculate Selection Advisable?}

Pre-freezing ejaculate selection is the basis of commercial semen freezing in domestic species, which ensures the post-thaw sample quality. However, in threatened or endangered species, it is necessary to preserve all the available ejaculates and hence designing methods to prevent the spermagglutination and/or urine contamination is important.

\section{Preventive measures}

Kojima et al. (2001) and Okano et al. (2004) observed that bladder catheterization, prior to electroejaculation, was effective in preventing urine contamination in Asian black bear. Urospermia could be caused by an electrical overstimulation (Okano et al. 2004), bladder repletion, the electroejaculation protocol, anaesthesia, individual sensitivity, etc. Wirtu et al. 2008 concluded that urination induced by applying pressure on the bladder or by preputial massage prior to electroejaculation did not prevent the contamination of the samples. In our 
experiments, bladder catheterization prior to electroejaculation only slightly reduced the percentage of urinecontaminated samples $(69.2 \%$ vs $57.4 \%)$, where as keeping the catheter in place during electroejaculation reduced the percentage to $35.5 \%$ (unpublished data). Another tested method to prevent urine contamination is to collect the ejaculates in different tubes (Chen et al. 2007). When we applied fractioned collection (several tubes per ejaculate), we observed that some of the collected tubes of urine-contaminated samples $(40 \%$ of total spermatozoa collected) were urine-free (unpublished data).

Agglutination may disappear by diluting the sample with protective media. On this basis, we have tested collecting the ejaculate directly on the extender (TesTris-fructose), effectively reducing the spermagglutination (Table 1), which can be beneficial in salvaging urospermic ejaculates too.

\section{Spermatozoa salvage}

Numerous treatments have been used to decontaminate urospermic samples: dilution with isoosmotic solutions, centrifugation and separation by gradient (Crich and Jequier 1978; Liu and Baker 1992; Okano et al. 2004; Wirtu et al. 2008). In horses, the addition of semen extender restored the motility of urine contaminated semen to that of the uncontaminated control sample; however, sperm washing procedures require centrifugation to remove urine and this procedure can damage the spermatozoa by causing urine crystal reconcentration in the pellet (Griggers et al. 2001). In bulls, only 5\% of motility was recovered after exposing the semen to hypoosmotic urine (Guthrie et al. 2002), but in bongo antelope (Tragelaphus eurycerus saaci), Wirtu et al. 2008 showed $0-50 \%$ recovery with proper treatments. We have determined that dilution and centrifugation of contaminated sample tend to improve the post-thawing spermatozoa viability (Table 2). Also, the change from hyperosmotic to hypoosmotic medium did not affect the acrosome integrity ( $87 \%$ of intact acrosomes).

Another possibility to avoid the negative effects of urospermia is the modification of urine $\mathrm{pH}$ and osmolality by orally delivering a saline solution (in human, Aust et al. 2008). Further research should be carried out on the freezability of the urine-contaminated samples.

Table 1. Brown bear sperm parameters (Mean \pm SEM) of semen obtained by two collection methods (empty tube vs tube with collection medium Tes-Tris-fructose)

\begin{tabular}{lcc}
\hline & Collection in medium & Collection in empty tube \\
\hline TM \% & $74.7 \pm 3.1$ & $73.9 \pm 3.7$ \\
PM \% & $36.0 \pm 2.5$ & $40.6 \pm 3.2$ \\
VAP $\mu$ /s & $100.7 \pm 3.9$ & $110.8 \pm 4.5$ \\
Agglutination & $0.8 \pm 0.1$ & $1.4 \pm 0.2$ \\
IP-PNA \% & $64.3 \pm 3.2$ & $62.4 \pm 3.0$ \\
n & 57 & 57 \\
\hline
\end{tabular}

TM, total motility; PM, progressive motility; VAP, velocity average path measured by CASA (ISAS; Proiser, Valencia, Spain). Spermagglutination subjective evaluation $0-4$ scale: 0 , no agglutination; 1 , light agglutination; 2 , moderate agglutination; 3 , high agglutination; IP/PNA, viable spermatozoa with intact acrosome (Flow cytometry).

Unpublished data.
Table 2. Post-thawed ejaculated semen parameters of brown bear urospermic samples subjected or not to pre-freezing wash (Tes-TrisFructose)

\begin{tabular}{|c|c|c|c|c|}
\hline & \multicolumn{2}{|c|}{ Washed } & \multicolumn{2}{|c|}{ Unwashed } \\
\hline & $\mathrm{n}$ & Mean \pm SEM & $\mathrm{n}$ & Mean \pm SEM \\
\hline JC-1 (\%) & 20 & $30.8 \pm 2.9$ & 17 & $28.4 \pm 3.7$ \\
\hline IP/PNA (\%) & 20 & $37.4 \pm 3.3$ & 17 & $36.9 \pm 3.7$ \\
\hline SYBR-14/IP (\%) & 20 & $36.5 \pm 3.6$ & 17 & $29.4 \pm 4.1$ \\
\hline
\end{tabular}

JC-1, spermatozoa with high mitochondrial membrane potential (Flow cytometry). IP/PNA, viable spermatozoa with intact acrosome (Flow cytometry). SYBR-14/IP, live spermatozoa (Flow cytometry).

Unpublished data.

\section{Special Features of Brown Bear Spermatozoa Assessment}

Published procedures of bear sperm assessment are quite limited. Thus, basic evaluation of bear ejaculates includes: volume, concentration (haemocytometer), motility (visual, therefore subjective), viability (eosinnigrosin staining) and morphology (optical microscopy, fixing samples with glutaraldehyde). Occasionally, authors apply other procedures to assess specific features of the sperm cell. Acrosome integrity in giant panda bear (Spindler et al. 2004) and Asian black bear (Chen et al. 2007) has been determined with rose bengal staining. Sperm capacitation in giant panda bear has been evaluated using atrial natriuretic peptide (Zhang et al. 2005) and different capacitation accelerating molecules (Spindler et al. 2004). For reason of high biological value of the samples and the lack of fertility data, it is necessary to apply other assessment techniques from domestic species, which might provide more reliable results to define sample quality.

There are automated systems that provide objective results of sperm concentration, motility, kinetic parameters and morphometry and their use has been validated in brown bear (Anel et al. 2003, 2007; Garcia-Macias et al. 2006b) and giant panda bear (Perez-Garnelo et al. 82003). We have also analysed different aspects of the cell physiology by using flow cytometry: cell viability, acrosome integrity, capacitation and mitochondrial membrane potential (Garcia-Macias et al. 2004). Chromatin status analysis is a critical protocol that provides interesting data on the quality of the sperm cell (Evenson et al. 2002) and which we have tested on bear spermatozoa (Garcia-Macias et al. 2006c).

In this sense, varying results have proved the need to adapt the methodologies to the special features of the target species. Thus, Garcia-Macias et al. (2005), using JC-1 to determine the mitochondrial membrane potential in bear spermatozoa, obtained reliable results in fresh and thawed samples, but not in pre-freezing analysis.

The detection of urine contamination (urospermia) is of major importance in brown bear ejaculates. There are several subjective methods to detect urospermia, such as colour (yellow), higher volume than expected, smell, etc. (Okano et al. 2006; Chen et al. 2007), but these can lead to wrong conclusions (if urine volume is low or if it is highly diluted) and do not show the physico-chemical characteristics of the contaminated sample. Some 


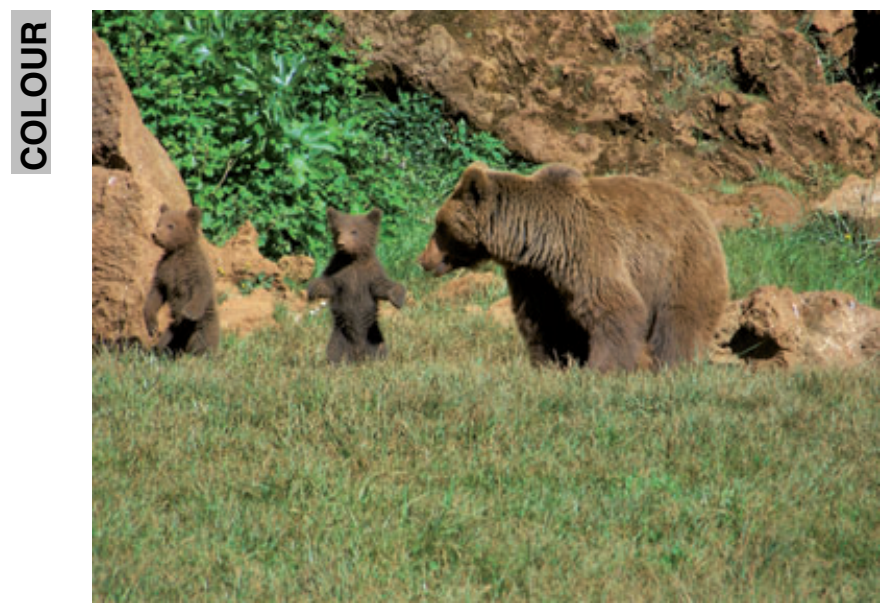

21Fig. 1. Brown bear female and their cubs in Cabarceno Nature Park

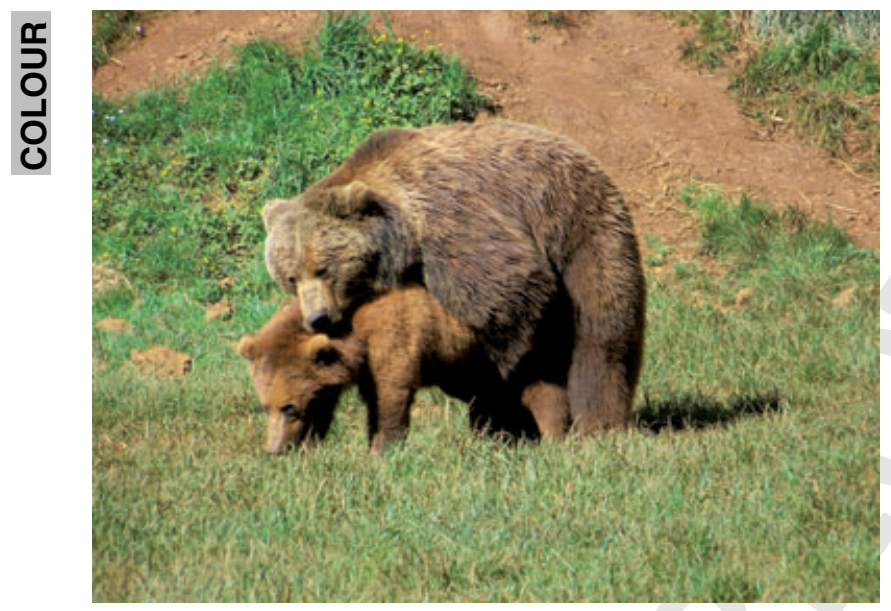

Fig. 2. Brown bear mating in Cabarceno Nature Park

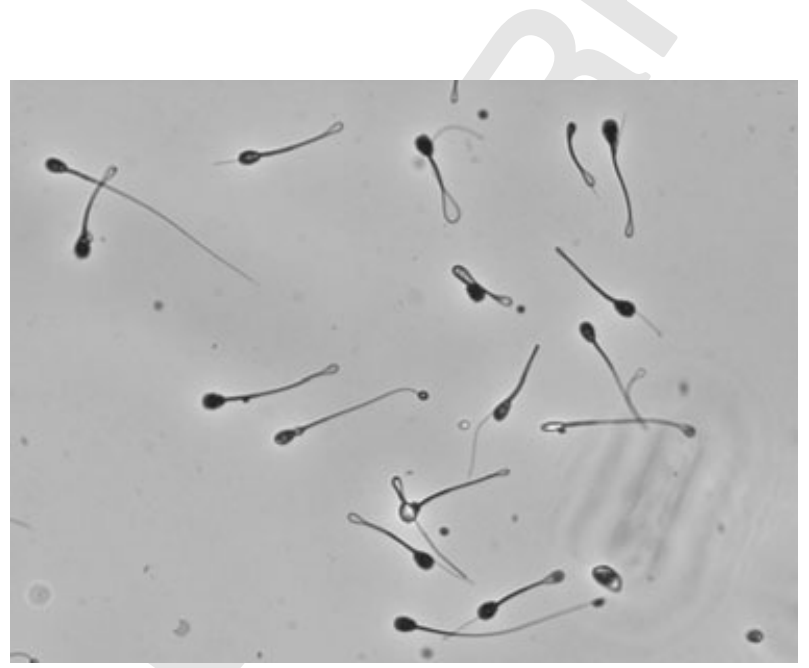

Fig. 3. Brown bear semen sample affected by hypoosmotic urine contamination

authors (Kojima et al. 2001 in Japanese black bear or Spindler et al. 2004 in giant panda bear) diagnosed urospermia by determining the $\mathrm{pH}$ (usually lower in

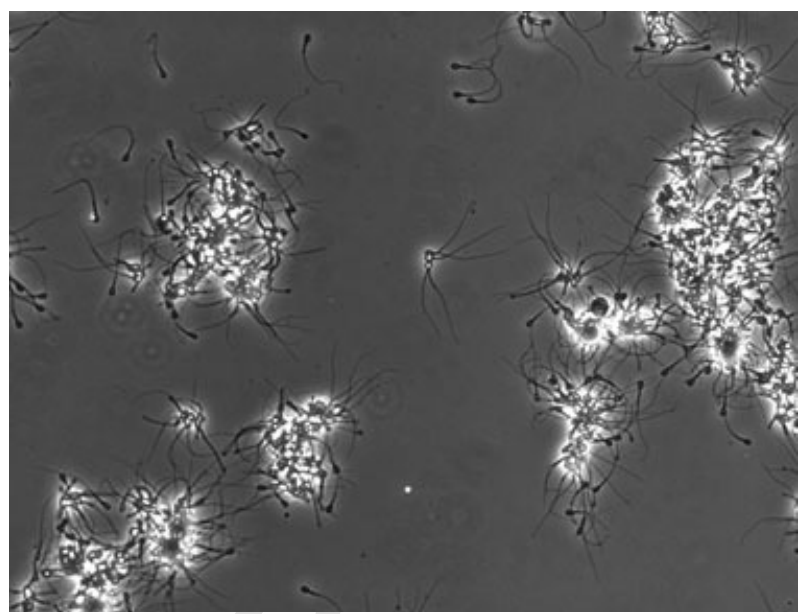

Fig. 4. Brown bear spermatozoa show very high agglutination

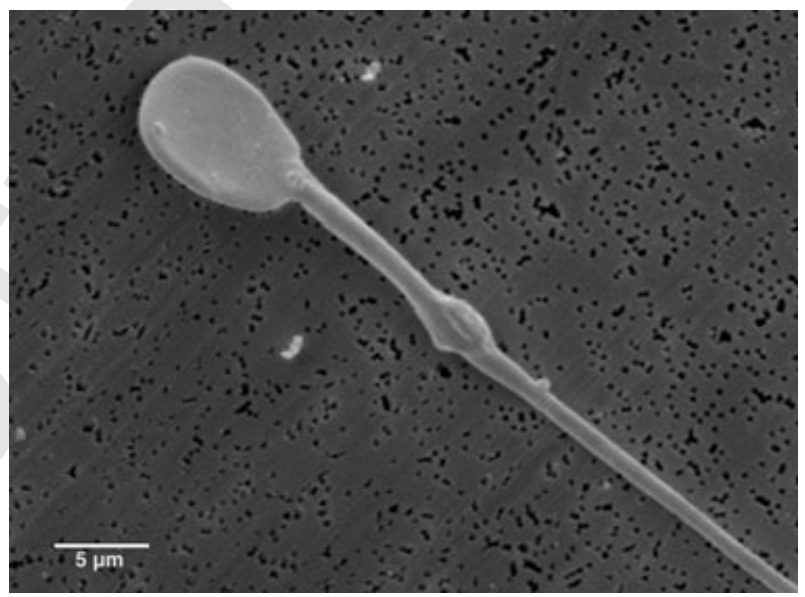

Fig. 5. A distal droplet of brown bear spermatozoon is observed under scanning electron microscopy photomicrography

contaminated samples). Indeed, we have observed that contaminated samples have an acidic $\mathrm{pH}$, but it is important to highlight that $\mathrm{pH}$ does not change if the contamination is low. Another indicator of urospermia is the noticeable change in osmolarity. However, field determination is difficult (it requires expensive and bulky equipment) and easier tests would be desirable.

These tests may be based on qualitative and/or semiquantitative detection of some urine components (e.g. urea). Early diagnosis with a quick test for urea detection (Althouse et al. 1989) allowed us to determine the presence of contamination (Martinez-Pastor et al. 2003), although it does not provide data on ejaculate osmolarity (essential to evaluate the contamination level).

\section{Freezing Brown Bear Spermatozoa}

Brown bear spermatozoa have a good 'freezability' according to scarce published data. However, in our case, more studies are required to achieve optimal results, because of the high biological value of the samples. These studies should include assays on 
domestic species extenders, comparisons with novel extenders, adjustment of cooling and freezing procedures, adaptation of the protocols to field conditions and adaptation of other technologies, such as sex sorting (Fickel et al. 2007).

Commercial extenders designed for other species are a practical solution for unexpected situations. Freezing brown bear semen with extenders used in other species, mainly bovids, has been reported with good results (Tris-buffered-egg yolk in Hokkaido brown bear, Ishikawa et al. 2002; Tris-citric acid-glucose-egg yolk in Japanesse black bear, Okano et al. 2004; egg yolklactose in giant panda: Seager et al. 1987; Tes-Tris-egg yolk in giant panda, Spindler et al. 2004 and Zhang et al. 2005). These studies used glycerol as cryoprotec-1 tant in percentages ranging from 4.7 to $8 \%$ and which was added in one or two steps.

Several physico-chemical aspects are important in spermatozoa preservation: extender composition and its effect on the plasma membrane, osmotic tolerance limits, hydraulic conductivity and cryoprotectant per-11 meability (Woods et al. 2004). The optimal cryoprotectant concentration depends on the species and on the cooling rates. Glycerol is essential for freezing, but it is also cytotoxic and thus the best concentration for each species and situation needs to be found (Fahy 1986). Okano et al. (2006) assayed final glycerol concentrations of $4,6,8,10$ and $12 \%$ in black bear semen, the best results being obtained between 4 and $6 \%$. At present, we have also assessed different glycerol concentrations $(2,4$, 6,8 and $10 \%$ ) in brown bear ejaculates, with the best results between 6 and $8 \%$ (unpublished data).

Freezing success requires a balance between cooling, freezing and thawing rates, as well as the application of the optimal cryoprotectant for each species (Hammadeh et al. 2001). Okano et al. (2004, 2006) used nitrogen vapours $(6 \mathrm{~cm}$ above liquid nitrogen surface during $15 \mathrm{~min}$ ) for freezing Japanese black bear sperm and obtained good results. Ishikawa et al. (2002) froze Hokkaido brown bear sperm using a procedure with several steps and keeping the straws at different distances above the liquid nitrogen $(30 \mathrm{~cm}, 4 \mathrm{~cm}$ and $2 \mathrm{~cm})$ and three freezing speeds. In giant panda semen, Spindler et al. (2004) applied very fast cooling rates $\left(-40^{\circ} \mathrm{C} / \mathrm{min}\right.$ during the first minute and $-100^{\circ} \mathrm{C} / \mathrm{min}$ immediately after) and they concluded that acrosomal status and 12 capacitation were not affected by this freezing model.

The use of programmable freezing equipments allows a more accurate study of the freezing procedures than using nitrogen vapours. In our experiments, standard cooling rates of $-20^{\circ} \mathrm{C}$ (from $5^{\circ} \mathrm{C}$ to $-100^{\circ} \mathrm{C}$ ) were adequate for freezing brown bear semen in a programmable biofreezer. At present, we are assaying different cooling rates $\left(-10^{\circ} \mathrm{C},-20^{\circ} \mathrm{C},-30^{\circ} \mathrm{C}\right)$. Olson et al. (2003) demonstrated that giant panda spermatozoa maintained a high viability after refrigeration times $\left(4^{\circ} \mathrm{C}\right)$ up to $48 \mathrm{~h}$. This could be an useful alternative, allowing freezing when it is convenient and not just after semen collection.

Macromolecule supplementation (lipoproteins, proteins and phospholipids) to the freezing extender is useful for stabilizing the plasma membrane and keeping high membrane permeability, allowing the adaptation to osmotic changes. This protective effect varies greatly among species and individuals (Gao et al. 1993; Thurston et al. 2002a,b; Holt et al. 2005). In reproductive biotechnology, the main source of these components is the egg yolk (Salamon and Maxwell 2000) and thus this product has been selected in all the aforementioned cryopreservation methods. However, the composition of egg yolk varies considerably and egg yolk represents a high sanitary risk (animal source). An alternative consists of purifying the protective component of egg yolk low density lipoproteins (LDL) (Moussa et al. 2002). Another option is to substitute egg derivates with soy lecitin (vegetal origin), which implies easy handling and standarization as well as no sanitary risks (Van Wagtendonk-de Leeuw et al. 2000; Aires et al. 2003; Gil 0 et al. 2003), although the high concentration of exogenous phospholipids can be harmful for spermatozoa (Hellemann and Jara 1997). To date, there is no information on the use of these alternative substances for bear semen cryopreservation. We have assayed diluents with egg yolk, LDL (from egg yolk, 10\%) and 1 soy bean (Andromed ${ }^{\circledR}$ Minitüb, Germany). The results obtained (Table 3 ) were better for the control extender $(20 \%$ egg yolk) and Andromed $\AA$; it is necessary to continue these studies on the use of egg yolk alternatives for bear semen extenders.

\section{Epididymal Spermatozoa: The Last Resort}

The epididymis is an important germplasm source and its collection is usually the only possibility of preserving gametes from high-value animals or endangered species (Leibo and Songsasen 2002; brown bear: Anel et al. 1999; giant panda: Perez-Garnelo et al. 2004). There are some differences between epididymal and ejaculated spermatozoa, but the functional maturity of those obtained from the cauda epididymis is high and many studies have found that they are fully capable of fertilizing an egg. In fact, cauda epididymis spermatozoa have been used in several assisted reproductive techniques and pregnancies and embryo production have been reported (Soler et al. 2003; Tsutsui et al. 2003; Hori et al. 2004; Ehling et al. 2006; Garde et al. 2006).We have carried out the recovery (Table 4) and freezing (preliminary results in Table 5) of epididymal spermatozoa from an adult male in a Cantabric brown bear wild 2 population that died accidentally (Anel et al. 1999).

Table 3. Post-thawed qualitative parameters (Mean \pm SEM) of brown bear ejaculated semen frozen with different extenders

\begin{tabular}{llll}
\hline$(\mathrm{n}=47)$ & $20 \%$ egg yolk & Andromed $^{\circledR}$ & $10 \%$ LDLs \\
\hline TM (\%) & $52.5 \pm 3.4$ & $44.4 \pm 3.1$ & $46.2 \pm 3.5$ \\
PM (\%) & $16.1 \pm 2.0$ & $11.4 \pm 1.4$ & $11.6 \pm 1.9$ \\
VAP $(\mu \mathrm{m} / \mathrm{s})$ & $65.4 \pm 3.4$ & $65.4 \pm 4.2$ & $56.2 \pm 4.1$ \\
LIN $(\%)$ & $35.8 \pm 1.0^{\mathrm{a}}$ & $35.1 \pm 1.1^{\mathrm{ab}}$ & $32.2 \pm 1.1^{\mathrm{b}}$ \\
IP/PNA (\%) & $62.9 \pm 3.7^{\mathrm{a}}$ & $56.2 \pm 3.4^{\mathrm{a}}$ & $39.0 \pm 5.7^{\mathrm{b}}$ \\
SYBR-14/IP (\%) & $59.1 \pm 3.9^{\mathrm{a}}$ & $54.8 \pm 3.9^{\mathrm{a}}$ & $35.3 \pm 6.0^{\mathrm{b}}$
\end{tabular}

${ }^{\mathrm{a}, \mathrm{b}}$ In the same row, different superscripts indicate significant differences $(\mathrm{p}<0.05)$.

TM, total motility; PM, progressive motility; VAP, velocity average path; LDLs, low density lipoproteins; LIN, Linearity measured by CASA (ISAS; Proiser, Valencia, Spain). IP/PNA: viable spermatozoa with intact acrosome (Flow cytometry). SYBR-14/IP: live spermatozoa (Flow cytometry).

Unpublished data. 
Table 4. Quantitative parameters of the cauda epididymis (CE) spermatozoa (spz), post-mortem recovered from a Cantabric brown bear (Anel et al. 1999)

\begin{tabular}{lccccc}
\hline & Epididymis $(\mathrm{g})$ & $\mathrm{CE}(\mathrm{g})$ & Sperm $(\mathrm{g})$ & $\mathrm{spz} / \mathrm{ml}$ & Total recovered spz \\
\hline Left & 7.10 & 2.81 & 0.09 & $4426 \times 10^{6}$ & $929 \times 10^{6}$ \\
Righ & 7.81 & 3.09 & 0.12 & & \\
\hline
\end{tabular}

Table 5. Pre-freezing (extended) and post-thawing sperm characteristics of the epididymal spermatozoa recovered post-mortem from a Cantabric brown bear: preliminary results (Anel et al. 1999)

\begin{tabular}{lccc}
\hline & $\begin{array}{c}\text { Total } \\
\text { motility (\%) }\end{array}$ & $\begin{array}{c}\text { Progressive } \\
\text { motility (\%) }\end{array}$ & $\begin{array}{c}\text { Intact } \\
\text { acrosomes (\%) }\end{array}$ \\
\hline Pre-freezing & 45 & 30 & 62 \\
Post-thawing & 25 & 15 & 29
\end{tabular}

Extender, Tes-Tris-Fructose-Glycerol-Egg yolk (325 mOsm $/ \mathrm{kg})$.

Motility analysis, CASA system (Motility Analyzer v. 7.4G, Hamilton-Thorne Research $^{\mathrm{TM}}$ ).

Acrosomes, phase contrast microscopy.

The initial quality and freezability of an epidydimal sample depends on handling factors such as deathfreezing interval (Martinez-Pastor et al. 2005a), which are difficult to control in wild species, genitals storage temperature until the processing (Kaabi et al. 2003) and the season during which the sample is taken (MartinezPastor et al. 2005b). Epididymal spermatozoa have specific features, especially regarding their physiological microenvironment and maturation status and this affects the specific adjustment of the cryopreservation protocols (Martinez-Pastor et al. 2006). On the basis all this, Anel et al. (1999) carried out an emergency assay for Cantabric brown bear sperm cryopreservation with three extenders (Tes-Tris-Fructose-Glycerol-Egg yolk) that differed in osmolarity and presence of additives like EDTA and Equex paste. The high osmolarity extender $(430 \mathrm{mOsm} / \mathrm{kg})$ showed the best results (unpublished data). Even when epididymal sperm presented lower quality compared with ejaculated semen, it could be 13 successfully used in IVF or ICSI procedures.

\section{Conclusions}

Brown bear semen freezing is currently feasible, but new studies are necessary to adapt sperm freezing protocols to the characteristics of brown bear ejaculates and to obtain a higher recovery on thawed samples allowing the creation of a Cantabric brown bear genetic resource bank.

\section{Acknowledgements}

We thank Vanesa García, Nerea González, Miguel Angel Marañón, the gamekeepers of the Cabarceno Nature Park (Roberto Aguilar, Manuel Álvarez, Julio Tamayo, Elena López) and the Fundación Oso de Asturias for their cooperation.

\section{Conflicts of interest}

Our experiments have been supported in part by CICYT (CLG200402178/BOS, CLG2007-63748/BOS), CANTUR S.A. and University of Leon. Felipe Martínez-Pastor was supported by the Juan de la Cierva program (Spanish Ministry of Science and Innovation).

\section{References}

Addison EM, Kolenosky GB, 1979: Use of ketamine hydrochloride and xylazine hydrochloride to immobilize black bears (Ursus americanus). J Wildl Dis 15, 253-258.

Aires VA, Hinsch KD, Mueller-Schoesser F, Bogner K, Mueller-Schoesser S, Hinsch E, 2003: In vitro and in vivo comparison of egg yolk-based and soybean lecithin-based extenders for cryopreservation of bovine semen. Theriogenology 60, 269-279.

Althouse GC, Seager SWJ, Varner DD, Webb GW, 1989: Diagnostic aids for the detection of urine in the equine ejaculate. Theriogenology 31, 1141-1148.

Anel L, Martinez F, Alvarez M, Anel E, Boixo JC, Kaabi M, Paz P, Chamorro C, Herraez P, 1999: Post-mortem spermatozoa recovery and freezing in a Cantabric brown bear (Ursus arctos): a preliminary report. Theriogenology 51, 277.

Anel L, Anel E, Alvarez M, Garcia-Macias V, Martinez F, Borragan S, Celada M, Herraez P, Paz P, 2003: Computerized analysis of sperm motility in European brown bear (Ursus arctos) semen. Theriogenology 59, 386.

Anel L, Martínez-Pastor F, Alvarez M, García-Macías V, Borragan S, Celada M, Martínez F, Chamorro CA, Herráez P, Anel E, Paz P, 2005: Basis for the establishment of germplasm banks for brown bear: spermatology. Reprod Domest Anim 40, 335.

Anel L, Garcia-Macias V, Martinez-Pastor F, Alvarez M, Borragan S, Bernardo J, Alves S, Chamorro C, Paz P, 2007: Effect of spermatozoa head morphometric dimensions on freezability in brown bear (Ursus arctos). Reprod Fertil Dev 19, 237.

Aust TR, Brookes S, Troup SA, Fraser WD, Lewis-Jones DI, 2008: Development and in vitro testing of a new method of urine preparation for retrograde ejaculation; the Liverpool solution. Fertil Steril 89, 885-891.

Blackshaw AW, Emmens CW, 1951: The interaction of $\mathrm{pH}$, osmotic pressure and electrolyte concentration on the motility of ram, bull and human spermatozoa. J Physiol $114,16-26$.

Blottner S, Hingst O, Meyer HH, 1995: Inverse relationship between testicular proliferation and apoptosis in mammalian seasonal breeders. Theriogenology 44, 321-327.

Bollwein H, Petschow K, Weber F, Leiding C, Stolla R, 2004: The incidence of agglutination and its influence on sperm quality and fertility of boar semen. Journal Berl Munch Tierarztl Wochenschr 117, 327-333.

Boone WR, Catlin JC, Casey KJ, Dye PS, Boone ET, Schuett RJ, 1999: Live birth of a bear cub following nonsurgical embryo collection. Theriogenology 51, 519-529.

Chen LM, Hou R, Zhang ZH, Wang JS, An XR, Chen YF, Zheng HP, Xia GL, Zhang MJ, 2007: Electroejaculation and semen characteristics of Asiatic black bears (Ursus thibetanus). Anim Reprod Sci 101, 358-364.

Craighead J, Hornocker M, Craighead F, 1969: Reproductive biology of young female grizzly bears. J Reprod Fertil Suppl 6, 447-475.

Crich JP, Jequier AM, 1978: Infertility in men with retrograde ejaculation: the action of urine on sperm motility, and a simple method for achieving antegrade ejaculation. Fertil Steril 30, 572-576.

Dehnhard M, Hildebrandt T, Knauf T, Jewgenow K, Kolter L, Göritz F, 2006: Comparative endocrine investigations in three bear species based on urinary steroid metabolites and volatiles. Theriogenology 66, 1755-1761.

Ehling C, Rath D, Struckmann C, Frenzel A, Schindler L, Niemann H, 2006: Utilization of frozen-thawed epididymal ram semen to preserve genetic diversity in Scrapie susceptible sheep breeds. Theriogenology 66, 2160-2164. 
Erickson A, Nellor J, 1964: Breeding biology of the black bear. In: Erickson A, Nellor J, Petrides G (eds), The Black Bear in Michigan. vol 4. East Lansing, MI: Michigan State University, pp. 5-45.

Evenson DP, Larson KL, Jost LK, 2002: Sperm chromatin structure assay: its clinical use for detecting sperm DNA fragmentation in male infertility and comparisons with other techniques. J Androl 23, 25-43.

Fahy GM, 1986: The relevance of cryoprotectant "toxicity" to cryobiology. Cryobiology 23, 1-13.

Fickel J, Wagener A, Ludwig A, 2007: Semen cryopreservation and the conservation of endangered species. Eur J Wildl Res 53, 81-89.

Gao DY, Ashworth E, Watson PF, Kleinhans FW, Mazur P, Critser JK, 1993: Hyperosmotic tolerance of human spermatozoa: separate effects of glycerol, sodium chloride, and sucrose on spermolysis. Biol Reprod 49, 112-123.

Garcia-Garitagoitia JL, Rey I, Doadrio I, 2003: Estudio genético del oso pardo cantábrico en Asturias. Tech. rep. CSIC, de Medio Consejería Ambiente, del Territorio Ordenación e del Principado Infraestructuras de Asturias. ?????, ?????.

Garcia-Macias V, Martinez-Pastor F, Martinez F, Gonzalez N, Alvarez M, Anel E, Paz P, Borragan S, Celada M, Anel L, 2005: Problems using JC-1 to assess mitochondrial status in brown bear (Ursus arctos) semen. Reprod Fertil Dev 17, 246.

Garcia-Macias V, Martinez-Pastor F, Alvarez M, Borragan S, Chamorro CA, Soler AJ, Anel L, de Paz P, 2006a: Seasonal changes in sperm chromatin condensation in ram (Ovis aries), Iberian red deer (Cervus elaphus hispanicus), and brown bear (Ursus arctos). J Androl 27, 837-846.

Garcia-Macias V, Martinez-Pastor F, Alvarez M, Paz P, Borragan S, Celada M, Anel E, Anel L, 2006b: Morphometric characterization of epididymal and ejaculated spermatozoa from brown bear (Ursus arctos). Reprod Fertil Dev 18, 217-218.

Garcia-Macias V, Martinez-Pastor F, Paz P, Alvarez M, Borragan S, Martinez F, Anel E, Anel L, 2006c: Morphometric and chromatin assessment in brown bear (Ursus arctos) ejaculated spermatozoa. Reprod Domest Anim 41, 329.

Garcia-Macias V, Martinez-Pastor F, Alvarez M, Paz P, Borragan S, Anel E, Mata M, Anel L, 2007: Use of a triplestain (SYBR-14/PI/MC540) for viability and capacitation assessment in thawed semen from brown bear (Ursus arctos). Reprod Fertil Dev 19, 239

Garde J, Martinez-Pastor F, Gomendio M, Malo AF, Soler AJ, Fernandez-Santos R, Esteso M, Garcia AJ, Anel L, Roldan ERS, 2006: The application of reproductive technologies to natural populations of red deer. Reprod Domest Anim 41, 93-112.

Garshelis DL, Hellgren EC, 1994: Variation in reproductive biology of male black bears. J Mammal 75, 175-188.

Gil J, Lundeheim N, Soderquist L, Rodriguez-Martinez H, 2003: Influence of extender, temperature, and addition of glycerol on post-thaw sperm parameters in ram semen. Theriogenology 59, 1241-1255.

Griggers S, Paccamonti DL, Thompson RA, Eilts BE, 2001: The effects of $\mathrm{pH}$, osmolarity and urine contamination on equine spermatozoal motility. Theriogenology 56, 613-622.

Guthrie HD, Liu J, Critser JK, 2002: Osmotic tolerance limits and effects of cryoprotectants on motility of bovine spermatozoa. Biol Reprod 67, 1811-1816.

Hammadeh ME, Szarvasy D, Zeginiadou T, Rosenbaum P, Georg T, Schmidt W, 2001: Evaluation of cryoinjury of spermatozoa after slow (programmed biological freezer) or rapid (liquid nitrogen vapour) freeze-thawing techniques. J Assist Reprod Genet 1, 364-370.
Hellemann C, Jara C, 1997: Efecto de un surfactante sobre la integridad de espermatozoides ovinos crioconservados. Arch Med Vet 29, 153-160.

Holt WV, Bennett PM, Voldbouev V, 1996: Genetic resource banks in wildlife conservation. J Zool London 238, 531544.

Holt WV, Medrano A, Thurston LM, Watson PE, 2005: The significance of cooling rates and animal variability for boar sperm cryopreservation: insights from the cryomicroscope. Theriogenology 63, 370-382.

Hori T, Ichikawa M, Kawakami E, Tsutsui T, 2004: Artificial insemination of frozen epididymal sperm in beagle dogs. J Vet Med Sci 66, 37-41.

Howell-Skalla LA, Cattet MRL, Ramsay MA, Bahr JM, 2002: Seasonal changes in testicular size and serum $\mathrm{LH}$, prolactin and testosterone concentrations in male polar bears (Ursus maritimus). Reproduction 123, 729-733.

Ishikawa A, Matsui M, Sakamoto H, Katagiri S, Takahashi Y, 2002: Cryopreservation of the semen collected by electroejaculation from the Hokkaido Brown Bear (Ursus arctos yesoensis). J Vet Sci. 64, 373-376.

IUCN, 2007: IUCN Red List of Threatened Species. Available at: http://www.iucnredlist.org.

Kaabi M, Paz P, Alvarez M, Anel E, Boixo JC, Rouissi H, Herraez P, Anel L, 2003: Effect of epididymis handling conditions on the quality of ram spermatozoa recovered post-mortem. Theriogenology 60, 1249-1259.

Kim SC, Kim HW, 1998: Effects of nitrogenous components of urine on sperm motility: an in vitro study. Int $\mathbf{J}$ Androl 21, 29-33.

Kojima E, Tsuruga H, Komatsu T, Murase T, Tsubota T, Kita I, 2001: Characterization of semen collected from beagles and captive Japanese black bears (Ursus thibetanus japonicus). Theriogenology 55, 717-731.

Laikre L, Andren R, Larsson HO, Ryman N, 1996: Inbreeding depression in brown bear Ursus arctos. Biol Conserv 76, 6972.

Lee J, Schweinsburg R, Kernan F, Haigh J, 1981: Immobilization of polar bears (Ursus maritimus, Phipps) with ketamine hydrochloride and xylazine hydrochloride. J Wildl Dis 17, 331-336.

Leibo SP, Songsasen N, 2002: Cryopreservation of gametes and embryos of non-domestic species. Theriogenology 57, 303-326.

Liu DY, Baker HW, 1992: Tests of human sperm function and fertilization in vitro. Fertil Steril 58, 465-483.

Makler A, David R, Blumenfeld Z, Better OS, 1981: Factors affecting sperm motility. VII. Sperm viability as affected by change of $\mathrm{pH}$ and osmolarity of semen and urine specimens. Fertil Steril 36, 507-511.

Martinez-Pastor F, Anel E, Alvarez M, Boixo JC, Chamorro C, Diaz A, Martinez F, Borragan S, Garde JJ, Anel L, 2003: A rapid test for urospermia detection in electroejaculates from several species. Theriogenology 59, 397.

Martinez-Pastor F, Guerra C, Kaabi M, Diaz-Corujo AR, Anel E, Herraez P, Paz P, Anel L, 2005a: Decay of sperm obtained from epididymes of wild ruminants depending on postmortem time. Theriogenology 63, 24-40.

Martinez-Pastor F, Guerra C, Kaabi M, Garcia-Macias V, Paz P, Alvarez M, Herraez P, Alvarez M, Herraez P, Anel L, 2005b: Season effect on genitalia and epididymal sperm from Iberian red deer, roe deer and Cantabrian chamois. Theriogenology 63, 1857-1875.

Martinez-Pastor F, Martinez F, Garcia-Macias V, Esteso MC Anel E, Fernandez-Santos MR, Soler AJ, Paz P, Garde J, Anel L, 2006: A pilot study on post-thawing quality of Iberian red deer spermatozoa (epididymal and electroejaculated) depending on glycerol concentration and extender osmolality. Theriogenology 66, 1165-1172. 
McMahon CG, Abdo C, Incrocci L, Perelman M, Rowland D, Waldinger M, Xin ZC, 2004: Disorders of orgasm and ejaculation in men. J Sex Med 1, 58-65.

Monga M, Robertst JA, 1994: Spermagglutination by bacteria: receptor-specific interactions. J Androl 15, 151-156.

Montgomery CA, 2002: Ranking the benefits of biodiversity: an exploration of relative values. J Environ Manage 65, 313326.

Moore HDM, Bush M, Celma M, Garcia AL, Hartman ND, Hearn JP, Hodges JK, Jones DM, Knight JA, Monsalv LE, Wildt DE, 1984: Artificial insemination in the Giant Panda (Ailuropoda melanoleuca). J Zool 203, 269-278.

Moussa M, Martinet V, Trimeche A, Tainturier D, Anton M, 2002: Low density lipoproteins extracted from hen egg yolk by an easy method: cryoprotective effect on frozen-thawed bull semen. Theriogenology 57, 1695-1706.

Okano T, Murase T, Tsubota T, 2004: Electroejaculation and semen cryopreservation of free-ranging Japanese black bears (Ursus thibetanus japonicus). J Vet Med Sci 66, 1371-1376.

Okano T, Murase T, Asano M, Tsubota T, 2006: Effects of final dilution rate, sperm concentration and times for cooling and glycerol equilibration on post-thaw characteristics of canine spermatozoa. J Vet Med Sci 66, 1359-1364.

Olson MA, Yan H, DeSheng L, Hemin Z, Durrant B, 2003: Comparison of storage techniques for Giant Panda sperm. Zoo Biol 22, 335-345.

Onuma M, Suzuki M, Uchida E, Niiyama M, Ohtaishi N, 2002: Annual changes in fecal estradiol-17beta concentrations of the sun bear (Helarctos malayanus) in Sarawak, Malaysia. J Vet Med Sci 64, 309-313.

Perez-Garnelo SS, Garde J, Pintado B, Borque C, Talavera C, Delclaux M, López M, de la Fuente J, 2004: Characteristics and in vitro fertilizing ability of Giant Panda (Ailuropoda melanoleuca) frozen-thawed epididymal spermatozoa obtained 4 hours postmortem: a case report. Zoo Biol 23, 279286.

Pommer AC, Rutllant J, Meyers SA, 2002: The role of osmotic resistance on equine spermatozoal function. Theriogenology 58, 1373-1384.

Pukazhenthi B, Noiles E, Pelican K, Donoghue A, Wildt D, Howard J, 2000: Osmotic effects on feline spermatozoa from normospermic versus teratospermic donors. Cryobiology 40, 139-150.

Salamon S, Maxwell WM, 2000: Storage of ram semen. Anim Reprod Sci 62, 77-111.

Seager SWJ, Dulensek EP, He G, Schaller GB, 1987: Giant Panda (Ailuropoda melanoleuca) semen collection, evaluation and freezing in Southwest China. In: ????? ??? (ed.), Proceedings of the 15th Annual Meeting of the Society for

18 Cryobiology. ?????, Tokyo, Japan, pp. 123-126.

Soler AJ, Garcia AJ, Fernandez-Santos R, Esteso M, Garde J, 2003: Effects of thawing procedure on post-thawed in vitro viability and in vivo fertility of red deer epididymal spermatozoa cryopreserved at $-196^{\circ} \mathrm{C}$. J Androl 24, 746756.

Spindler RE, Huang Y, Howard JG, Wang P, Zhang H, Zhang G, Wildt DE, 2004: Acrosomal integrity and capacitation are not influenced by sperm cryopreservation in the Giant Panda. Reproduction 127, 547-556.

Suzuki M, Kaji K, Nigi H, 1992: Annual changes of testis size, seminiferous tubules and plasma testosterone concentration of wild Sika deer (Cervus nippon yesoensis Heude, 1884) in Hokkaido. J Vet Med Sci 54, 551-556.

Taberlet P, Bouvet J, 1994: Mitochondrial DNA polymorphism, phylogeography, and conservation genetics of the brown bear Ursus arctos in Europe. Proc R Soc Lond B Biol Sci 255, 195-200.

Thurston LM, Siggins K, Mileham AJ, Watson PF, Holt WV, 2002a: Identification of amplified restriction fragment length polymorphism markers linked to genes controlling boar sperm viability following cryopreservation. Biol Reprod 66, $545-554$.

Thurston LM, Watson PF, Holt WV, 2002b: Semen cryopreservation: a genetic explanation for species and individual variation? Cryo Letters 23, 255-262.

Tsubota T, Kanagawa H, Takahashi K, Yasue K, Fukunaga S, 1985: Observation of sexual behaviour under captive condition in Hokkaido brown bears (Ursus arctos yesoensis). Jpn J Anim Reprod 31, 203-210.

Tsubota T, Yamamoto K, Mano T, Yamanaka M, Kanagawa $\mathrm{H}$, 1991: Immobilization of the free-ranging Hokkaido brown bear, Ursus arctos yesoensis with ketamine hydrochloride and xylazine hydrochloride. J Vet Med Sci 53, 321322.

Tsutsui T, Wada M, Anzai M, Hori T, 2003: Artificial insemination with frozen epididymal sperm in cats. $\mathrm{J}$ Vet Med Sci 65, 397-399.

Tsutsui T, Hori T, Nakashige T, Narushima E, Hara T, Akikawa T, Nose N, Saito K, Shichiri S, Hashizaki F, Komiya T, 2006: Semen quality in a Giant Panda (Ailuropoda melanoleuca) in relation to estrus of a nearby resident female panda. Theriogenology 66, 1803-1806.

Van Wagtendonk-de Leeuw AM, Haring RM, Kaal-Lansbergen LM, Den Daas JH, 2000: Fertility results using bovine semen cryopreserved with extenders based on egg yolk and soy bean extract. Theriogenology 54, 57-67.

Wildt DE, 1997: Genome resource banking. In: Karow AM, Critser JK (eds), Reproductive Tissue Banking. Academic Press, London, pp. 399-440.

Wildt DE, 2000: Genome resource banking for wildlife research, management, and conservation. ILAR J 41, 228234.

Wirtu G, Pope CE, MacLean RA, Godke RA, Paccamonti DL, Dresser BL, 2008: Reversal motility loss in bongo antelope (Tragelaphus eurycerus isaaci) spermatozoa contaminated with hyposmotic urine during electroejaculation. Anim Reprod Sci 103, 392-397.

Woods EJ, Benson JD, Agca Y, Crister JK, 2004: Fundamental cryobiology of reproductive cells and tissues. Cryobiology 48, 146-156.

Zhang M, Tang H, Shen G, Zhou B, Wu Z, Peng Z, Zhang J, Yan J, Xia G, 2005: Atrial natriuretic peptide induces an acrosome reaction in giant panda spermatozoa and enhances their penetration of salt-stored porcine oocytes. Theriogenology 64, 1297-1308.

20 Submitted: $\mathrm{xx}$ Xxxxx 200x

Author's address (for correspondence): P de Paz, ITRA-ULE, Molecular Biology, University of León, 24071, León, Spain. E-mail: ppazc@unileon.es 